\title{
Patho-anatomic findings in finisher pigs, sows, and piglets detected during veterinary slaughterhouse inspection
}

\author{
Vladimir Vecerek ${ }^{1}$, Eva Voslarova ${ }^{1}$, Zbynek Semerad $^{2}$ \\ ${ }^{1}$ University of Veterinary and Pharmaceutical Sciences Brno, Faculty of Veterinary Hygiene and Ecology, \\ Department of Animal Protection and Welfare and Veterinary Public Health, Brno, Czech Republic \\ ${ }^{2}$ State Veterinary Administration, Prague, Czech Republic
}

Received May 10, 2020

Accepted December 21, 2020

\begin{abstract}
The number of patho-anatomic findings detected during the veterinary examination of slaughtered pigs was analyzed. From 2010 to 2017, a total of 20550072 finisher pigs, 484710 sows, and 94279 piglets were slaughtered in the Czech Republic. By comparing the overall amount of patho-anatomic findings expressed as an index of the ratio of the number of findings to the number of slaughtered animals, the highest incidence of patho-anatomic findings was determined in piglets (index 1.52), followed by sows (index 1.23), and the lowest in finisher pigs (index 0.81 ). The most numerous was the occurrence of chronic findings (finisher pigs: index $0.724 \%$, sows: 0.926 , piglets: 0.877 ). Furthermore, a high frequency of acute findings was found (finisher pigs: index 0.037 , sows: 0.207 , piglets: 0.373 ). The findings of traumatic and parasitic nature were significantly $(P<0.001)$ lower than those of chronic and acute character. The differences in the total number of findings and in the number of findings by the type of damage were significant $(P<0.001)$ between the individual pig categories. The results show that the worst health condition was observed in piglets, followed by sows, and the best in finisher pigs. Furthermore, the number of findings was significantly decreasing in finisher pigs $(\mathrm{r}=-0.7143$, $P=0.047)$; no significant change was found in sows $(\mathrm{r}=-0.643, P=0.086)$; however, it was significantly increasing in piglets $(\mathrm{r}=+0.857, P=0.007)$. Therefore, there is a particular need for health improvement in piglets and also in sows.
\end{abstract}

Swine, slaughter, meat inspection, incidence of lesions

After the end of the feeding period (finisher pigs) or after the termination of the reproductive use (sows) or after the removal from fattening (piglets), the pigs are transported to a slaughterhouse, slaughtered and further processed. The requirement for these pigs is clinical health and well-being corresponding to the requirements for animals slaughtered for the production of meat and other pork products. After the slaughter, the pigs are inspected as a part of veterinary health surveillance of meat and other animal products made from slaughtered pigs. The results of the postmortem veterinary inspection of pigs may be used to assess the level of health and, where appropriate, the condition of the animals slaughtered. The level of health, the trends of its development and the nature of damage may vary for finisher pigs, sows, and piglets. Data collected from a high number of animals show the overall level of animal health and provide an important insight into the current level of pig husbandry and transport to slaughterhouses.

Several studies attempted to identify and quantify the condemnation of pig carcasses in slaughterhouses (Lis 1999, 2002; Kozak et al. 2003; Vecerek et al. 2004; Mateus-Vargas et al. 2011; Ceccarelli et al. 2018; Pereira et al. 2018). Some authors analyzed the total number of patho-anatomic changes observed during the postmortem inspection. Lis (1999) found pathological lesions in 33.21\% of pigs slaughtered in Poland in 1987 and in $41.43 \%$ of pigs slaughtered in Poland in 1997. In 2000, Lis (2002) found pathological 
lesions in $49.09 \%$ of pigs slaughtered in Poland. Januskeviciene et al. (2010) analyzed pathological lesions in the livestock (including pigs) slaughtered in Lithuania from 2000 to 2009 . They found the highest number of pathologic lesions in clinically healthy pigs $(14.92 \%)$ and the lowest number in poultry $(0.95 \%)$. The majority of lesions in poultry, pigs, and cattle were classified as the lesions typical of non-infectious diseases.

Hansson et al. (2000) and Kongsted and Sorensen (2017) compared the results of an official postmortem slaughterhouse inspection of pigs from different rearing systems. Hanss on et al. (2000) found a significant difference in the postmortem inspection of pigs reared conventionally and those reared according to organic standards in Sweden: 28\% of conventionally and $17 \%$ of organically reared pigs had one or more registered lesion. Kongsted and Sorensen (2017) compared slaughter lesions in pigs from conventional indoor, conventional free-range, and organic free-range production systems in Denmark. Whereas pairwise comparisons of the two free-range production systems did not reveal any significant differences, both conventional free-range and organic free-range production systems were associated with an increased incidence of lesions compared with the conventional indoor systems.

The published studies focused on the incidence of patho-anatomic changes in finisher pigs; the differences in results of postmortem examinations between different categories of pigs have not been analyzed yet. The aim of this study was to compare the level of health of slaughtered finisher pigs, sows, and piglets on the basis of the number of patho-anatomic findings found during the veterinary examination of pigs in slaughterhouses in terms of the overall level of health, the trend of its development, and the character of health damage in the individual categories of pigs.

\section{Materials and Methods}

Data on the numbers of patho-anatomic findings in finisher pigs, sows and piglets reared and slaughtered in slaughterhouses in the Czech Republic in the period from 2010 to 2017 were obtained in cooperation with the State Veterinary Administration. The national database where data on results of all postmortem inspections carried out by state veterinary inspectors in the Czech slaughterhouses are collected was used.

For each pig category, the total number of animals slaughtered and the total number of patho-anatomic findings of intravital origin detected within the postmortem veterinary inspection in the slaughterhouse was found. From the obtained data, the index of the ratio of the number of patho-anatomic findings of intravital origin to the number of slaughtered animals was calculated and compared among the pig categories.

Furthermore, the numbers of patho-anatomic findings in terms of the nature of damage (acute, chronic, traumatic, parasitic, other) in finisher pigs, sows, and piglets reared and slaughtered in the Czech Republic in the period 2010 to 2017 were processed in the same way.

In all categories of pigs, the development of the number of patho-anatomic findings during the monitored period was further monitored.

The results were analyzed using the statistical package Unistat 5.6. (Unistat Ltd., London, England). Statistical comparisons between the frequencies of the categorical variables of interest were performed with Chi-square test (with Yates correction) within the $2 \times 2$ contingency table procedure. When the frequencies in the contingency table were lower than 5, Fisher's exact test was used instead of Chi-square test. To assess the trend during the monitored years, Spearman rank correlation coefficient including its significance was calculated. A P-value $<0.05$ was considered significant.

\section{Results}

The total number of patho-anatomic findings in slaughtered finisher pigs, sows, and piglets is given in Table 1. A highly significant $(P<0.001)$ difference was found between the incidence of patho-anatomic findings expressed as an index of the ratio of the number of patho-anatomic findings to the number of slaughtered animals among the individual categories of pigs. The highest incidence of patho-anatomic findings was found in piglets (index 1.52), followed by sows (index 1.23), with the lowest one found in finisher pigs (index 0.81). 
Table 1. Comparison of the total number of patho-anatomic findings in slaughtered finisher pigs, sows, and piglets.

\begin{tabular}{lccr}
\hline Pig category & Finisher pigs & Sows & Piglets \\
\hline Number of slaughtered animals & 20550072 & 484710 & 94279 \\
$\begin{array}{l}\text { Number of patho-anatomic findings - intravital } \\
\text { Index of the ratio of the number of patho-anatomic }\end{array}$ & 16632271 & 595171 & 143700 \\
findings to the number of slaughtered animals & $0.809^{\mathrm{c}}$ & $1.228^{\mathrm{b}}$ & $1.524^{\mathrm{a}}$ \\
\hline
\end{tabular}

a,b,c - Indices with different superscripts within a row differ significantly $(P<0.001)$

A comparison of the numbers of patho-anatomic findings in terms of acute, chronic, parasitic, traumatic and other lesions in finisher pigs, sows and piglets is presented in Table 2 and Fig. 1. The results show that the most frequent is the occurrence of chronic findings (finisher pigs: index 0.724\%, sows: 0.926, piglets: 0.877). Furthermore, especially in piglets and sows, a high frequency of acute findings was present (finisher pigs index: 0.037, sows: 0.207 , piglets: 0.373 ). Findings of traumatic nature were significantly lower than those of chronic and acute character. Findings of parasitic origin were reported to a greater extent only in finisher pigs (finisher pigs: index 0.040 , sows 0.009 , and piglets $0.016)$. The differences in the incidence of patho-anatomic findings of different origins were highly significant $(P<0.001)$ in all pig categories. The differences in the incidence of patho-anatomic findings of different origins between finisher pigs, sows and piglets were significant $(P<0.001)$ with the exception of traumatic findings for which no difference $(P>0.05)$ was observed between sows and piglets.

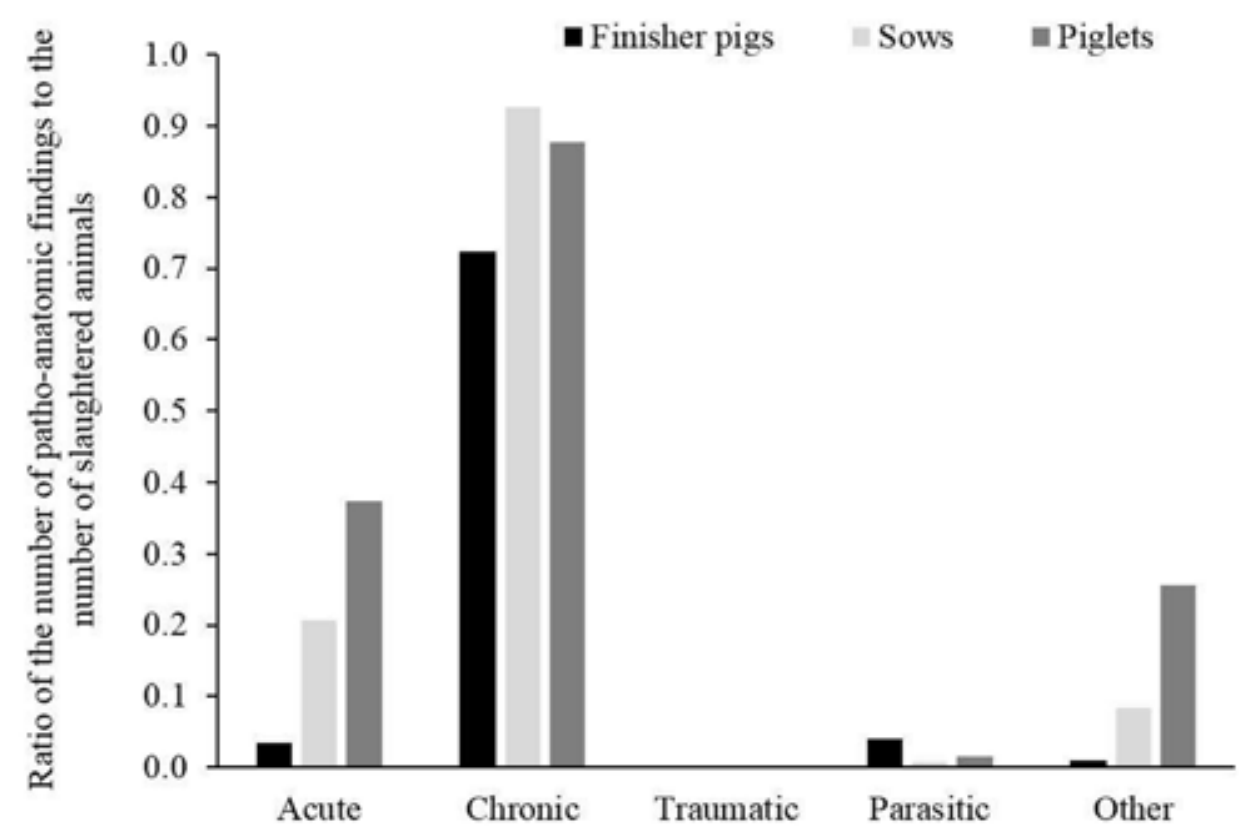

\section{Patho-anatomic findings}

Fig. 1. Comparison of numbers of patho-anatomic findings in terms of acute, chronic, parasitic, traumatic and other damage in slaughtered finisher pigs, sows and piglets. 
Table 2. Comparison of numbers of patho-anatomic findings according to their origin and/or character of the course of the disease in slaughtered finisher pigs $(\mathrm{n}=20550072)$, sows $(\mathrm{n}=484710)$, and piglets $(\mathrm{n}=94279)$.

\begin{tabular}{lrrrrrr}
\hline & \multicolumn{2}{c}{ Finisher pigs } & \multicolumn{3}{c}{ Sows } & \multicolumn{2}{c}{ Piglets } \\
\cline { 2 - 7 } Findings & \multicolumn{1}{c}{ number } & \multicolumn{1}{c}{$\%$} & number & \multicolumn{1}{c}{$\%$} & number & $\%$ \\
\hline Acute & 691816 & $3.37^{\mathrm{c}, \mathrm{x}}$ & 100251 & $20.68^{\mathrm{b}, \mathrm{w}}$ & 35183 & $37.32^{\mathrm{a}, \mathrm{w}}$ \\
Chronic & 14882608 & $72.42^{\mathrm{c}, \mathrm{v}}$ & 449059 & $92.64^{\mathrm{a}, \mathrm{v}}$ & 82692 & $87.71^{\mathrm{b}, \mathrm{v}}$ \\
Traumatic & 17416 & $0.08^{\mathrm{b}, \mathrm{z}}$ & 743 & $0.15^{\mathrm{a}, \mathrm{z}}$ & 152 & $0.16^{\mathrm{a}, \mathrm{z}}$ \\
Parasitic & 823109 & $4.01^{\mathrm{a}, \mathrm{w}}$ & 4134 & $0.85^{\mathrm{c}, \mathrm{y}}$ & 1473 & $1.56^{\mathrm{b}, \mathrm{y}}$ \\
Other & 217322 & $1.06^{\mathrm{c}, \mathrm{y}}$ & 40983 & $8.46^{\mathrm{b}, \mathrm{x}}$ & 24200 & $25.67^{\mathrm{a}, \mathrm{x}}$ \\
\hline
\end{tabular}

a,b,c - Percentages with different superscripts within a row differ significantly $(P<0.001)$

$\mathrm{v}, \mathrm{w}, \mathrm{x}, \mathrm{y}, \mathrm{z}$ - Percentages with different superscripts within a column differ significantly $(P<0.001)$.

The development of the number of patho-anatomic findings in finisher pigs, sows and piglets between 2010 and 2017 is shown in Fig. 2. Comparing the trends in the incidence of the total number of patho-anatomic findings expressed by the coefficient of rank correlation between the annual index of the number of patho-anatomic findings and the individual years of the monitored period, the coefficients for finisher pigs were -0.7143 $(P=0.047)$, sows $-0.6429(P=0.086)$ and piglets $+0.8571(P=0.007)$.

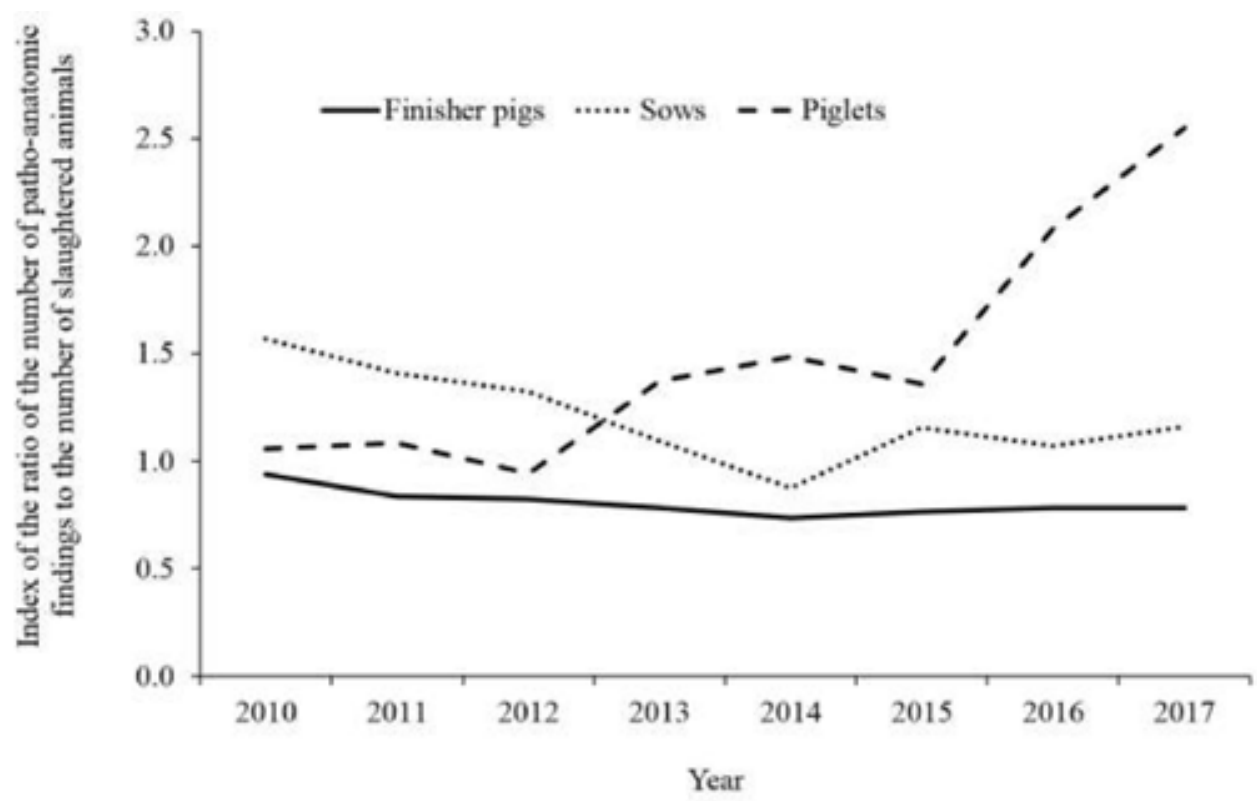

Fig. 2. Comparison of trends in the total number of patho-anatomic findings in slaughtered finisher pigs, sows and piglets.

\section{Discussion}

The high incidence of patho-anatomic findings in slaughtered piglets documents the fact that piglets are transported to the slaughterhouse due to lower fitness or a worse health condition, which is reflected in the high number of their patho-anatomic findings. 
Similarly, sows transported to the slaughterhouse represent older animals past the prime of their fitness which is why they show relatively frequent patho-anatomic findings when examined in the slaughterhouse, but at a lower level than piglets. Finisher pigs transported to the slaughterhouse are young animals in a good shape and therefore, with a lower incidence of patho-anatomic findings detected during the postmortem examination compared to sows and piglets. However, it is apparent from the results that, in particular for piglets, it is necessary to re-evaluate the conditions of rearing and transport to the slaughterhouse, since the impact of these conditions on the health of piglets slaughtered in the slaughterhouse leads to unfavourable incidence of patho-anatomic findings. Proper care for pigs in the early production stages is critical. Weaning is associated with stress-related morbidity and pigs in the first weaner stage have an increased risk of poor body condition and lethargic behaviour (van Staaveren et al. 2018). In sows, the level of health is more favourable in terms of the occurrence of the total number of patho-anatomic findings found in slaughterhouses during postmortem examination, however, the total number of patho-anatomic findings in sows is high and it is therefore also necessary to further improve the conditions of their rearing and transport for slaughter. Fogsgaard et al. (2018) described the clinical condition of cull sows on-farm and found wounds in $54.6 \%$ of animals, $10 \%$ of them showed signs of changed gait, and $0.8 \%$ were obviously lame. Furthermore, Thodberg et al. (2019) documented that transportation from a farm to a slaughterhouse leads to deterioration of the clinical condition of the sows, as indicated by the increased prevalence of superficial skin lesions, different types of wounds as well as signs of dehydration. In finisher pigs, the level of health is the best in terms of the total number of patho-anatomic findings after slaughter compared to sows and piglets, nevertheless, even here, the overall number of findings indicates that it is necessary to further increase the health condition of slaughtered pigs. Comparing the numbers of pathological lesions in clinically healthy animals slaughtered in Lithuania, Januskeviciene et al. (2010) found the highest percentage in pigs and the lowest in poultry. The results of our work also confirm a considerably higher incidence of patho-anatomic findings in pigs compared to poultry (broiler chickens, laying hens, turkeys) slaughtered in the Czech Republic in the same period (Vecerek et al. 2019; Vecerkova et al. 2019).

In addition to the total number of patho-anatomic findings in different categories of pigs, the origin of these findings was also monitored. The findings are important for identifying the causes of health damage with an impact on the patho-anatomic findings investigated during the examination of pigs in the slaughterhouse. In all categories of pigs, the most frequent was the occurrence of chronic findings. The high number of chronic lesions points to processes that have been taking place in pigs in all three categories for a long time. Intensive farming systems are confronted with a number of animal health and welfare issues (Martinez-Miro et al. 2016; Nordquist et al. 2017; Woods 2019). Procedures that compromise welfare and biological functioning should be identified, abandoned, and replaced by alternatives that do not adversely affect animal welfare (Nordquist et al. 2017).

The higher extent of acute damage found in piglets and sows alerts to recent damage on farms shortly before transport. Our findings as well as observations regarding the occurrence of lesions in cull sows by Fogsgaard et al. (2018) call for further investigation of the welfare of piglets and sows in the last period of their life, which until now has received almost no scientific attention.

Conversely, damage of parasitic origin was detected at a higher rate among finisher pigs compared to sows and piglets. These findings draw attention to the persistence of parasitic invasions in finisher pigs. Similarly, Ceccarelli et al. (2018) found ascariasis in percentages that varied little over time. It is one of the most common pathological findings both in conventionally and organically reared pigs (Hansson et al. 2000). The lower rates 
of disability in sows can be explained by the fact that older pigs withstand worm burdens better and inhibit larval migration, thus being free of infection or being asymptotic carriers of low-grade infections due to prior exposure (Hansson et al. 2000).

Traumatic lesions indicate the level of pig handling, particularly when transported to a slaughterhouse. The rates of carcass degradation and mortality records during transport provide information on the possible welfare status of the transported animals and the severity of problems encountered en route (Smulders and Algers 2009). A positive detection is that the findings of traumatic origin were low in all pig categories. This is also in agreement with the decreasing trend in the mortality of pigs transported for slaughter (Voslarova et al. 2017). However, further improvement in transport conditions is desirable in order to reduce both transport-related mortality and the number of traumatic injuries in pigs that arrive alive.

Analyzing the postmortem findings in pigs slaughtered during three selected years in Poland, Lis $(1999,2002)$ found increasing numbers of pig carcasses in which pathological lesions were detected. Pathological lesions were found in $33.21 \%$ of pigs slaughtered in 1987 , in $41.43 \%$ of pigs slaughtered in 1997 , and in $49.09 \%$ of pigs slaughtered in 2000 . However, it is unclear from their results whether this negative trend affected all categories of pigs. The evaluation of the development of the number of patho-anatomic findings detected in slaughterhouses during the monitored period in our study shows a positive trend of reducing the incidence of patho-anatomic findings in finisher pigs. In sows, the number of findings did not change during the monitored period, but in piglets there was a negative trend of increasing incidence of patho-anatomic findings. Therefore, it is necessary to focus on eliminating the transport of piglets of compromised health and inferior fitness to slaughterhouses (in accordance with the requirements of European legislation which states that only healthy animals in a condition corresponding to a healthy animal can be slaughtered in the slaughterhouse), so that the trend can be reversed in favour of reducing the incidence of patho-anatomic findings in slaughtered piglets.

In conclusion, the number of patho-anatomic findings in pigs slaughtered in slaughterhouses shows the worst level of health in piglets, followed by sows, and on the contrary, the best in finisher pigs. The highest number of findings in all pig categories was of chronic character, followed by acute; parasitic and traumatic lesions were low. The trend in the level of health of slaughtered finisher pigs was significantly improving in the monitored period, there was no significant change in sows, and it was considerably worsening for piglets. The need to improve the health condition of pigs slaughtered in slaughterhouses is particularly apparent in piglets and sows.

\section{Acknowledgments}

This study was supported by the Veterinary Scientific Committee of the Czech Republic.

\section{References}

Ceccarelli M, Leprini E, Sechi P, Iulietto MF, Grispoldi L, Goretti E, Cenci-Goga BT 2018: Analysis of the causes of the seizure and destruction of carcasses and organs in a slaughterhouse in central Italy in the 2010-2016 period. Ital J Food Saf 7: 40-44

Fogsgaard KK, Herskin MS, Thodberg K 2018: Transportation of cull sows - A descriptive study of the clinical condition of cull sows before transportation to slaughter. Transl Anim Sci 2: 280-289

Hansson I, Hamilton C, Ekman T, Forslund K 2000: Carcass quality in certified organic production compared with conventional livestock production. J Vet Med B Infect Dis Vet Public Health 47: 111-120

Januskeviciene G, Paulauskas V, Dailidaviciene J, Juozaitiene V 2010: Analysis of pathologic lesions in the livestock and poultry slaughtered in the meat establishments of Lithuania. Vet Zootec 52: 33-42

Kongsted H, Sorensen JT 2017: Lesions found at routine meat inspection on finishing pigs are associated with production system. Vet J 223: 21-26

Kozak A, Vecerek V, Chloupek P, Tremlova B, Malena M 2003: Veterinary meat inspection of pig carcasses in the Czech Republic during the period of 1995-2002. Vet Med-Czech 48: 207-213 
Lis H 1999: An evaluation of veterinary inspection of slaughtered animals and meat in Poland between 1987-1997. Med Weter 55: 243-246

Lis H 2002: Results of veterinary inspection of slaughtered animals and meat in Poland in 2000. Med Weter 58: 267-269

Martinez-Miro S, Tecles F, Ramon M, Escribano D, Hernandez F, Madrid J, Orengo J, Martinez-Subiela S, Manteca X, Ceron JJ 2016: Causes, consequences and biomarkers of stress in swine: an update. BMC Vet Res 12: 171

Mateus-Vargas RH, Jimenez-Loaiza EM, Alfaro-Zuniga CE, Passos-Pequeno A 2011: Analysis of the most common causes of viscera condemnation in pigs (liver, kidney, heart), in a slaughterhouse of Costa Rica, and its economical implication. Arch Lebensmittelhyg 62: 88-95

Nordquist RE, van der Staay FJ, van Eerdenburg F, Velkers FC, Fijn L, Arndt SS 2017: Mutilating procedures, management practices, and housing conditions that may affect the welfare of farm animals: Implications for welfare research. Animals 7: 12

Pereira PR, Caprioli RA, Hammerschmitt ME, Sonne L, Pavarini SP, Driemeier D 2018: Intestinal lesions in pigs slaughtered in Rio Grande do Sul, Brazil. Pesqui Vet Brasil 38: 823-831

Smulders FJM, Algers B 2009: Welfare of production animals: assessment and management of risks. Wageningen Academic Publishers, Wageningen, $588 \mathrm{p}$.

Thodberg K, Fogsgaard KK, Herskin MS 2019: Transportation of cull sows - Deterioration of clinical condition from departure and until arrival at the slaughter plant. Front Vet Sci 6: 28

Van Staaveren N, Diaz JAC, Manzanilla EG, Hanlon A, Boyle LA 2018: Prevalence of welfare outcomes in the weaner and finisher stages of the production cycle on 31 Irish pig farms. Ir Vet J 71: 9

Vecerek V, Kozak A, Malena M, Chloupek P, Pistekova V 2004: Organs of slaughter pigs as a source of potential risk for human health in the Czech Republic during the years 1995-2002. Vet Med-Czech 49: 75-78

Vecerek V, Vecerkova L, Voslarova E 2019: Comparison of the frequency of patho-anatomic findings in laying hens with findings in broiler chickens and turkeys detected during post-mortem veterinary inspection. Poult Sci 98: $5385-5391$

Vecerkova L, Voslarova E, Vecerek V 2019: Comparison of the welfare of laying hens, broiler chickens and turkeys in terms of bird health as surveyed during inspection in slaughterhouses. Acta Vet Brno 88: 243-248

Voslarova E, Vecerek V, Passantino A, Chloupek P, Bedanova I 2017: Transport losses in finisher pigs: Impact of transport distance and season of the year. Asian-Australas J Anim Sci 30: 119-124

Woods A 2019: Decentring antibiotics: UK responses to the diseases of intensive pig production (ca. 1925-65). Palgr Communic 5: 41 